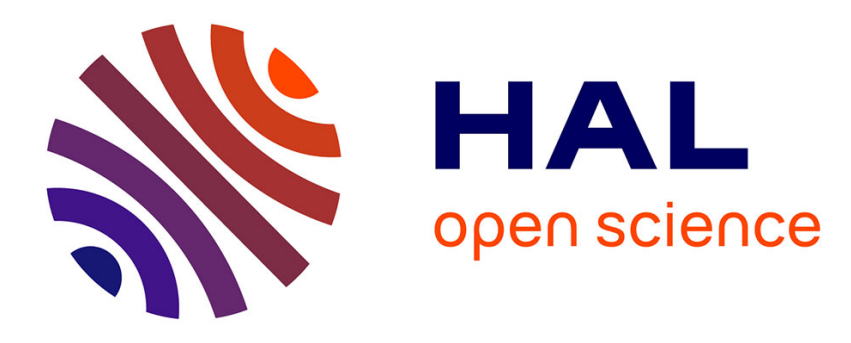

\title{
Capacity decisions with demand fluctuations and carbon leakage
}

Guy Meunier, Jean-Pierre Ponssard

\section{To cite this version:}

Guy Meunier, Jean-Pierre Ponssard. Capacity decisions with demand fluctuations and carbon leakage. 2013. hal-00347650v2

\section{HAL Id: hal-00347650 \\ https://hal.science/hal-00347650v2}

Preprint submitted on 17 Apr 2013 (v2), last revised 2 Dec 2013 (v3)

HAL is a multi-disciplinary open access archive for the deposit and dissemination of scientific research documents, whether they are published or not. The documents may come from teaching and research institutions in France or abroad, or from public or private research centers.
L'archive ouverte pluridisciplinaire HAL, est destinée au dépôt et à la diffusion de documents scientifiques de niveau recherche, publiés ou non, émanant des établissements d'enseignement et de recherche français ou étrangers, des laboratoires publics ou privés. 


\title{
ECOLE POLYTECHNIQUE
}

\section{CAPACITY DECISIONS WITH DEMAND FLUCTUATIONS} AND CARBON LEAKAGE

\author{
Guy MEUNIER \\ Jean-Pierre PONSSARD
}

Cahier $n^{\circ}$ 2013-08 (revised version 2008-16)

\section{DEPARTEMENT D'ECONOMIE}

Route de Saclay

91128 PALAISEAU CEDEX

(33) 169333033

http://www.economie.polytechnique.edu/

mailto:chantal.poujouly@polytechnique.edu 


\title{
Capacity decisions with demand fluctuations and carbon leakage.
}

\author{
Guy Meunier ${ }^{a, b}$ and Jean-Pierre Ponssard ${ }^{b *}$ \\ ${ }^{a}$ INRA-AliSS UR1303, 65 bd de Brandebourg, 94205 Ivry-sur-Seine, France \\ ${ }^{b}$ CNRS-Ecole Polytechnique, route de Saclay, 91120 Palaiseau, France
}

April 2013

\begin{abstract}
For carbon-intensive, internationally-traded industrial goods, a unilateral increase in the domestic $\mathrm{CO}_{2}$ price may result in the reduction of the domestic production but an increase of imports. In such sectors as electricity, cement or steel, the trade flows result more from shortterm regional disequilibria between supply and demand than from international competition. This paper formalizes this empirical observation and characterizes its impact on leakage. Domestic firms invest in home plants under uncertainty; then, as uncertainty unfolds, they may source the home market from their home plants or from imports. We prove that there would be no leakage in the short-term (without capacity adaptation) but there would be in the long-term (with capacity adaption). Furthermore, the larger the uncertainty the larger the leakage is. We also characterize the impacts of uncertainty on the (short-term and long-term) pass-through rates. In the concluding section we briefly discuss the implications of these results for the evaluation of climate policies.
\end{abstract}

JEL Classification: D81, D92, Q56, L13.

Keywords: carbon leakage, demand fluctuations, capacity decisions.

*Email adresses: guy.meunier@ivry.inra.fr, jean-pierre.ponssard@polytechnique.edu 


\section{Introduction}

When a country A implements a unilateral climate policy carbon leakage refers to the fact that the reduction of emissions in country A may be partly offset by the increase of emissions in the rest of the world.

The literature on carbon leakage has been initiated by Rutherford (1992) and Felder and Rutherford (1993) who coined the term "leakage". Carbon leakage plays a major role in the evaluation and design of alternative climate policies (Droege and Cooper, 2009; Hood, 2010). The empirical importance of the issue has generated a large number of models which evaluate the ex ante consequences of unilateral climate policies and the relative merits of remedies.

Several channels through which leakage could arise have been identified. The two most scrutinized channels are: the energy-market and the termsof-trade channels. This paper focuses on the terms-of-trade channel, also related to the competitiveness issue (i.e. that a unilateral climate policy may reduce national production and encourage imports). Most analyses are made in a deterministic framework so that capacity and production decisions are not distinguished and the influence of demand fluctuations is not considered.

In some trade-exposed and energy intensive sectors capacity decisions are governed by long term anticipated national supply and demand conditions. ${ }^{1}$ Capacity shortages in one region may trigger imports from regions which have excess capacities. For instance the short term capacity constraints observed in Europe around 2005-2007 explain better the trade patterns for cement and steel than the pressure of international competition between the EU and some specific non EU countries (Hourcade et al., 2008). So far the consequences of this form of trade on carbon leakage have not been recognized. Our objective is to formalize this empirical observation and characterize its impacts on carbon leakage.

We use a partial equilibrium model for a sector consisting of multinationals. All firms provide the same good to the home market using capacity in home or in foreign (i.e. the rest of the world where capacity is infinitely large). The cost structure is such that under certainty it would always be

\footnotetext{
${ }^{1}$ Trade-exposed and energy intensive sectors are also denominated as "sensitive" sectors. A sector is "sensitive" under two conditions: (Grubb and Neuhoff, 2006) the impact of the $\mathrm{CO}_{2}$ price is high relative to its value added (value at stake), it is highly exposed to international trade (import intensity). If both conditions are satisfied sectoral leakage is high. Typical sensitive sectors are: cement, steel, basic chemicals, aluminum...
} 
preferable to deliver to the home market via home location rather than via a foreign location: imports take place only if capacity at home is binding. Firms first decide on their capacity at home based on an uncertain future home demand. Then the demand is known and firms compete $\grave{a}$ la Cournot under capacity constraints at home. The analysis is carried on assuming linearity in the long run average cost function (investment and production) and in the demand function. Import costs are also assumed to be linear. The demand function includes an additive random parameter uniformly distributed over a given range, the larger the range, the larger the demand variability. We assume a constant $\mathrm{CO}_{2}$ emission factor for home and foreign production.

We distinguish between short term and long term effects. Suppose home unilaterally adopts a more stringent climate policy (i.e. increases the price for $\mathrm{CO}_{2}$ emissions); in the short term the capacities are given, in the long term the capacities are adapted to the change in the $\mathrm{CO}_{2}$ price. With no uncertainty, an increase in the $\mathrm{CO}_{2}$ price would lead to a decrease in the level of capacity and home production, but it would not induce relocation. With an uncertain demand, we show that the reduction of home production is amplified and some relocation occurs. The short term leakage rate is null while the long term leakage rate is positive and increasing with the level of demand uncertainty. Our model allows for the analysis of demand uncertainty on the pass through rate, i.e. the ratio of the increase in the product price relative to the increase of the carbon cost. It will be shown that the short term pass through rate is lower than the long term one.

The rest of the paper is organized as follows. The relation with the literature is discussed in Section 2. The model is described in Section 3 and analyzed in Section 4. The concluding section discusses applications and some direction for theoretic extensions.

\section{Related literature}

There is a consequent literature on carbon leakage. This literature identifies several channels through which leakage could arise, evaluates the consequences of unilateral climate policies and the relative merits of remedies. The bulk of the literature consist in numerical simulations of policies with multi-countries multi-sectors general equilibrium models. ${ }^{2}$

\footnotetext{
${ }^{2}$ The supplement 2 of Energy Economics vol 34 on border carbon adjustment edited by Böhringer et al . (2012) is a good illustration of this literature.
} 
The two most scrutinized channels for leakage are: the energy-market and the terms-of-trade channels. ${ }^{3}$ The reduction of the demand for fossil fuels in emissions-constraint countries induce a reduction of the fossil fuels world prices and an increase of their consumption in other countries. The term-oftrade channel is related to the competitiveness of trade-exposed and energy intensive industries. The rises of the production costs of regulated producers induces a positive shift of the production of unregulated producers.

Ordinarily the energy-driven channel generates a larger fraction of the total leakage than the terms-of-trade channel. But competitiveness issues are an important political issue. This explains its disproportionate role in the design of emission trading schemes (see Hood, 2010, for a review of how existing or forthcoming schemes in Australia, California, Europe, New Zealand ... are influenced by competitiveness issues).

This paper focuses on the terms-of-trade channel. Two main approaches have been commonly used to quantify the associated form of leakage. One approach consists in assuming that home and foreign products are imperfect substitutes (e.g. Fischer and Fox, 2012); the other one is built on imperfect competition à la Cournot (e.g. Babiker, 2005; Ponssard and Walker, 2008; Meunier and Ponssard, 2012) or monopolistic competition (e.g. Balistreri and Rutherford, 2012). The underlying explanation for intra-industry trade in these approaches is in line with the main body of the literature on international trade. Usually, intra-industry trade is explained by imperfect substitutability between home and foreign production, economies of scale and imperfect competition (Krugman, 1979, 1980; Brander, 1981).

We introduce a different rationale for intra-industry trade. We do consider a homogeneous product and Cournot competition but the existence of interlocking international oligopolies and national strategic trade barriers limit the pressure of international competition. International trade is due to regional capacity constraints and intra-firm flows. For conceptual simplicity, and analytical tractability, the design of our model eliminates the other forms of trade (imperfect substitutability and Cournot competition between national firms).

\footnotetext{
${ }^{3}$ Several other channels have been identified: the diffusion of new green technologies can induce a negative leakage (Golombek and Hoel, 2004; Gerlagh and Kuik, 2007), subsequent changes of wealth can induce a positive or negative leakage (Elliott and Fullerton, 2013), and the change of the marginal environmental damage modifies the optimal emissions in other countries (see for instance the work on environmental coalitions by Carraro and Siniscalco, 1993; Barrett, 1994).
} 
The motivation for our framework comes from the empirical literature on leakage for some specific trade-exposed and energy intensive industries. In Hourcade et al. (2008) (see chapter 3 entitled Deep-dive study: the EU cement and steel sectors) the authors investigate the reasons for the recent peak of imports observed in Europe in 2007. They strongly discount that this peak may come from an increase in international competition. International price comparisons exhibit a low correlation coefficient suggesting loosely connected regional markets at the world level. Their explanation relies on the world concentration in these markets and on the regional disequilibria between supply and demand. For cement, they show that non EU imports clearly responded to capacity constraints (the typical case being Spain). The imports came from various and changing sources, and not from dedicated foreign capacities.

These factual observations have been embedded in some applied numerical studies. For instance Demailly and Quirion (2008) and the Cement Sustainability Initiative report (WBCSD, 2009) elaborate multi-regional models of the world cement industry over a 30 year time horizon. Regional supply and demand conditions determine regional capacities and international trade flows come from the imbalances caused by myopic optimization.

The electricity sector provides another empirical context in which our framework may be relevant. It is a clear example in which demand is uncertain and short term capacity constraints play a major role in the selection of the optimal technology mix. Regional flows are significant and come from regional imbalances between supply and demand. It is also a sector in which there are interlocking regional oligopolies. Finally the development of regional ETS schemes makes leakage issues important for the economic analysis of these schemes. Bushnell and Chen (2012) discuss leakage for the Californian electricity sector. In their model, capacity constraints are introduced through a quadratic production function.

The objective in the present paper is to analyze the carbon leakage associated with this specific form of international or regional trade. We identify and explore the consequences of a unilateral change in a climate policy in an analytic model which allows the distinction between short term (without capacity adaptation) versus long term (with capacity adaptation) effects. In an empirical analysis the consequences of this assumption relative to the other forms of trade would naturally need be weighted. 


\section{The model}

\subsection{Assumptions}

The model is kept simple for analytical tractability. Extensions are discussed in the concluding section. Let us consider the market for a homogeneous good. The total quantity produced is denoted $q$. The inverse demand function is assumed to be linear and random : $p(q, \theta)=a+\lambda \theta-b q$, in which $a$ and $b$ are two positive parameters. Uncertainty is introduced through the dimensionless random variable $\theta$ which is assumed to be uniformly distributed on the interval: $[-1,+1]$ with density $1 / 2$ and the parameter $\lambda$ (in $€$ per unit) which measures the range of demand variations, the case of no uncertainty corresponds to $\lambda=0$. This parameter or the ratio $\lambda / a$ (dimensionless) will be referred to as demand variability.

The good is produced by an oligopoly consisting of $n$ identical firms. Each firm has access to two technologies: a home one and a foreign one. To produce with the home technology the firm should first invest in capacity. In the short-term the firm cannot produce more than its capacity at home but it can import.

The (annualized) cost of a unit of capacity is $c_{k}$ (in $€ /$ unit). With a unit of capacity the firm can produce at most one unit of the good for a variable cost $c_{h}$ (in $€ /$ unit). The variable cost includes the impact of the $\mathrm{CO}_{2}$ regulation. The cost function for the foreign technology involves a linear production cost and no investment cost. The marginal cost of imports is denoted $c_{f}$ (in $€$ /unit).

The production cost should be interpreted as an average delivered cost to the home market from foreign plants that have excess capacity relative to their own home markets. Assuming that the home market is small relative to the foreign market explains that there is no capacity constraint for imports. It is explicitly assumed that producers control all imports to their home market. As discussed in Section 2 this assumption may be more or less realistic depending on the sector under analysis.

Three assumptions are made on the parameters values. In case of no uncertainty the home technology would be preferred to the foreign one, $c_{k}+c_{h}<c_{f}$ and the demand would be high enough to make production worthwhile, $a>c_{h}+c_{k}$. Furthermore, the range of demand variations is limited so that in all demand states, in the short term, it is worth producing with the home technology: $0 \leq \lambda \leq a-c_{h}$. 
The decision process takes place in two steps. First, each firm decides its home capacity. Second, for each value of $\theta$ each firm chooses its home production and its imports (capacities are fixed). Firms compete in quantities, $\grave{a}$ la Cournot. Total capacity is denoted $k$, total home production is denoted $q_{h}$ and imports $q_{f}$. To alleviate notations we do not index firms individual production and capacity. All equilibriums are symmetric.

We consider open-loop Nash equilibrium; when firms invest they do not take into account the strategic effects of their investment on the production of their rivals. These strategic effects would obscure the core mechanism at stake. Furthermore, the only symmetric Nash equilibrium of the game is the open-loop one.

We want to study the influence of the demand variability $\lambda$ and the $\mathrm{CO}_{2}$ price through the variable $\operatorname{cost} c_{h}$ on the equilibrium total capacity to be denoted $k_{n}^{*}\left(\lambda, c_{h}\right)$ or simply $k_{n}^{*}$.

\subsection{Equilibrium investments}

For ease of exposition, we present the case of a monopoly, the oligopoly situation is described in Appendix ). The monopoly long term profit $\pi(k)$ for a given capacity choice $k$ is given by:

$$
\pi(k)=\int_{-1}^{+1} \max _{\left(q_{h}<k, q_{f}\right)}\left[p q-c_{h} q_{h}-c_{f} q_{f}\right] \frac{1}{2} d \theta-c_{k} k .
$$

The integrand represents the firm's short-term profit once $k$ has been chosen. The probability that a state occurs is $1 / 2 \mathrm{~d} \theta, \theta$ being uniformly distributed over $[-1,1]$. In each state $\theta$, the firm selects $q_{h}$ and $q_{f}$ to maximize its short-term profit $p q-c_{h} q_{h}-c_{f} q_{f}$ with $q=q_{h}+q_{f}$ and subject to $q_{h} \leq k$.

In the short-term, three situations can occur depending on the level of the demand. In low demand states, the firm has excess capacity and produces the monopoly unconstrained quantity $\left(q_{h}=\left(a+\theta-c_{h}\right) / 2\right)$ without importing $\left(q_{f}=0\right)$. For intermediate levels of the demand, the firm produces at full capacity $\left(q_{h}=k\right)$ and does not import $\left(q_{f}=0\right)$. Finally, when demand is large the firm produces at full capacity and imports. The overall quantity produced is then determined by the cost of imports $\left(q=\left(a+\theta-c_{f}\right) / 2\right)$. The occurrence of these situations depends on the amplitude of demand variation and the level of capacity chosen by the firm. If demand variability is sufficiently large all three situations arise in equilibrium. 
In the long term, the firm chooses $k$ to maximizes its profit (1). The firm should equalize the marginal cost of a capacity with the expected short term marginal profit which is the shadow price of the capacity constraint (i.e. $\left.q_{h} \leq k\right)$. This flow of revenue is constituted of two integrals: the first one is the integral of the difference $p+p^{\prime} k-c_{h}$ obtained when the capacity sets the price in intermediate demand situations; the second term is the integral of $c_{f}-c_{h}$ the short term cost reduction when demand is large and the firm imports.

Lemma 1 If demand variability is sufficiently large, the equilibrium capacity of the industry is:

$$
k_{n}^{*}=\frac{n}{n+1} \frac{1}{b}\left[a-\frac{c_{h}+c_{f}}{2}+\lambda\left(1-2 \frac{c_{k}}{c_{f}-c_{h}}\right)\right] .
$$

And, there are two thresholds $\theta^{-}$and $\theta^{+}$such that

\begin{tabular}{c|c|c|c|} 
& $-1 \leq \theta \leq \theta^{-}$ & $\theta^{-}<\theta<\theta^{+}$ & $\theta^{+}<\theta \leq 1$ \\
\hline$q_{h}$ & $\frac{n}{n+1} \frac{a-c_{h}}{b}$ & $k_{n}^{*}$ & $k_{n}^{*}$ \\
$q_{f}$ & 0 & 0 & $\frac{n}{n+1} \frac{a-c_{f}}{b}-k_{n}^{*}$
\end{tabular}

The proof is in Appendix B.

\section{Results}

In this section the consequences of an environmental policy such as the introduction of a $\mathrm{CO}_{2}$ emissions tax, which would consists in an increase of the home variable cost $c_{h}$ are analyzed. We consider the effect of such a policy on: the home investment, the leakage rate and the pass-through rate. We obtain analytical results and provide a numerical illustration of each point. The specifications of the illustration are detailed in Appendix A.

\subsection{Home investments}

Let us first consider how home capacity is influenced by an increase of the home variable cost, and how the amplitude of this change is affected by demand variability. 


\section{Proposition 1}

- The optimal capacity decreases with respect to the $\mathrm{CO}_{2}$ price,

- this effect is larger the larger the demand variability $\lambda$ :

$$
\frac{\partial k^{*}}{\partial c_{h}} \leq 0 ; \frac{\partial^{2} k^{*}}{\partial c_{h} \partial \lambda} \leq 0 .
$$

The proof is in C.1.

An increase of the $\mathrm{CO}_{2}$ price does, indeed, reduce investment and production in the regulated country. More interestingly, this effect is larger the larger the variability of home demand.

The role of demand variability could be understood by considering the equilibrium first-order condition. The equilibrium capacity is such that the expected marginal revenue from a capacity is equal to the complete cost $c_{h}+c_{k}$. The reduction of the capacity induced by the change of the variable cost ensures that this relation holds. With no demand uncertainty $(\lambda=$ $0)$, the capacity is equal to the production and determines the price in all demand states. However, when demand varies the capacity sets the price less frequently. Therefore, a larger adjustment of the capacity is necessary to maintain the equilibrium relationship between the marginal revenue and the long-term cost.

The implication of this proposition is that a model that does not account for demand uncertainty will underestimate the effect of the $\mathrm{CO}_{2}$ regulation on investment, and the larger the variability is the larger the mistake will be.

\section{Numerical illustration}

This result is illustrated on Figure 1. With our calibration, as the $\mathrm{CO}_{2}$ price increases from zero up to $40 € / \mathrm{t}$ the optimal capacity drops by $12 \%$. This may be compared to a $6 \%$ drop in case of no uncertainty. 


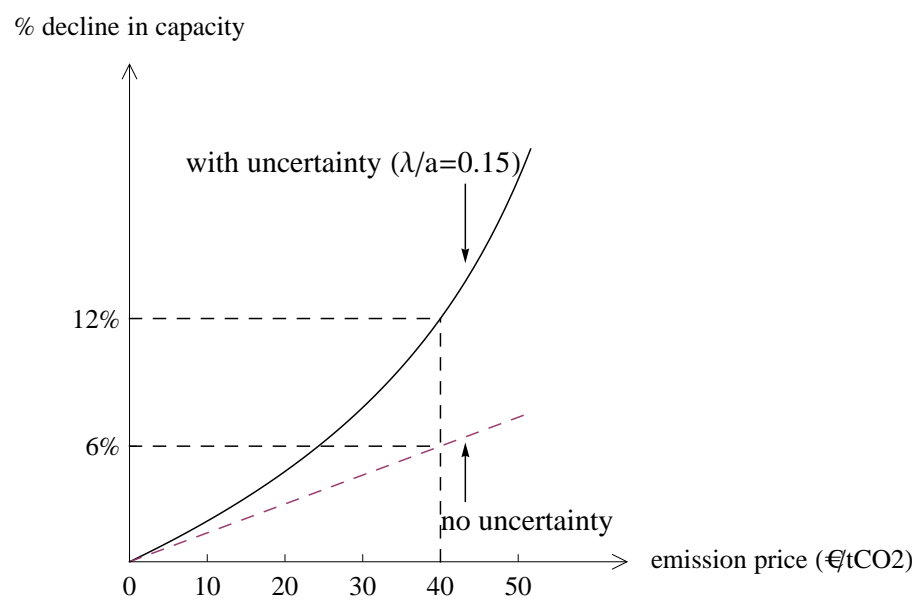

Figure 1: Percent decline in capacity with respect to the $\mathrm{CO}_{2}$ price, with and without demand variations.

This can be understood by considering how the optimal capacity depends on one side on the $\mathrm{CO}_{2}$ price for a given value of variability at $15 \%$ (Figure 4a) and on the other side on variability for a given value of the $\mathrm{CO}_{2}$ price taken at $40 € / \mathrm{t}$ (Figure $4 \mathrm{~b})$.

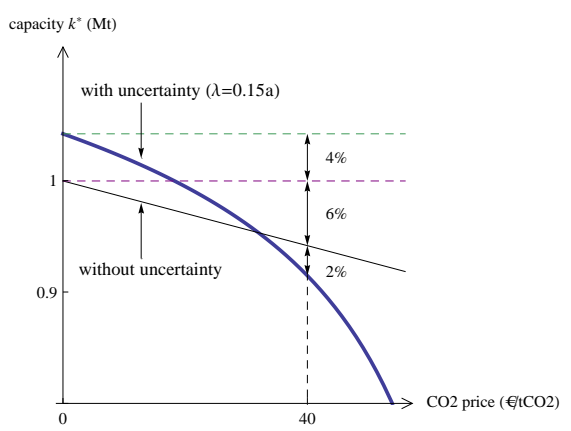

(a) The effect of the $\mathrm{CO}_{2}$ price

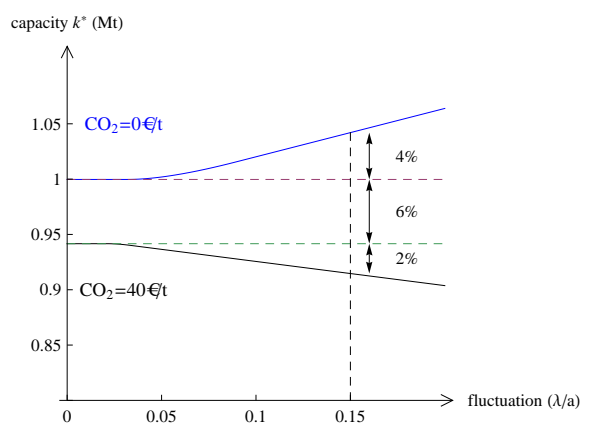

(b) The effect of the variability

Figure 2: Individual capacity as a function of the $\mathrm{CO}_{2}$ price (a) and demand variability (b).

\subsection{Leakage}

Let us discuss the effect of the implementation of a carbon policy on the leakage rate. We consider the value of this indicator in the short and long 
term. We consider that in the short term the capacity is fixed at $k_{n}^{*}\left(\lambda, c_{h}\right)$ and that in the long term this capacity varies according to the carbon policy to become $k_{n}^{*}\left(\lambda, c_{h}+\Delta c_{h}\right)$.

To precisely describe the various indicators we need to introduce some notations. Let us denote $q_{h}\left(k, c_{h}, \theta\right)$ and $q_{f}\left(k, c_{h}, \theta\right)$ the short term production of an oligopoly of $n$ firms in which each firm has a capacity $k / n$. The expressions of these quantities are given by (15) in Appendix C1.

The leakage is the increase of foreign emissions that follows the implementation of a carbon policy. The leakage rate is the ratio between the rise of emissions abroad and the decrease of home emissions. If foreign production and home production have the same emission rate, the short term leakage rate is:

$$
L_{S T}=\frac{\mathbb{E}\left[q_{f}\left(k_{n}^{*}\left(c_{h}\right), c_{h}+\Delta c_{h}, n, \theta\right)-q_{f}\left(k^{*}\left(c_{h}\right)_{n}, c_{h}, n, \theta\right)\right]}{\mathbb{E}\left[q_{h}\left(k^{*}\left(c_{h}\right)_{n}, c_{h}, n, \theta\right)-q_{h}\left(k_{n}^{*}\left(c_{h}\right), c_{h}+\Delta c_{h}, n, \theta\right)\right]} .
$$

And the long term leakage rate is:

$$
L_{L T}=\frac{\mathbb{E}\left[q_{f}\left(k_{n}^{*}\left(c_{h}+\Delta c_{h}\right), c_{h}+\Delta c_{h}, n, \theta\right)-q_{f}\left(k^{*}\left(c_{h}\right)_{n}, c_{h}, n, \theta\right)\right]}{\mathbb{E}\left[q_{h}\left(k^{*}\left(c_{h}\right)_{n}, c_{h}, n, \theta\right)-q_{h}\left(k_{n}^{*}\left(c_{h}+\Delta c_{h}\right), c_{h}+\Delta c_{h}, n, \theta\right)\right]} .
$$

\section{Proposition 2}

- The short term leakage rate is null.

- The long term leakage rate is increasing with respect to the level of demand variability. It is independent of the market structure.

The proof is in C.2. We also defined observed short term and long term leakage rates. The observed rates are the rates in a particular state $\theta$. The formal definition of these indicators is similar to (4) and, (5) without the expectation operator. Note that the short term and long term rates $L_{S T}$ and $L_{L T}$ are the ratio of the expected changes of productions and not the expectation of the observed rates, which, in our sense, does not have a sensible economic interpretation. We do not formally analyzed the observed indicators but they are computed for the numerical simulations below. 


\section{Numerical illustration}

In the short term imports are determined by the capacity constraint, there is no leakage. In the long term, capacity is reduced taking into consideration demand variations and the $\mathrm{CO}_{2}$ price. Ex post the firm decides to import or not for each demand realization given the new capacity. The situation is depicted in Figure 3(a). Suppose the observed demand corresponds to $\theta=.2$. The consumption with the zero $\mathrm{CO}_{2}$ price corresponds to point $\mathrm{A}$; with the $40 € / \mathrm{t} \mathrm{CO}_{2}$ price it is at $\mathrm{B}$; the level of imports corresponds to the segment $\mathrm{BC}$. The observed leakage rate corresponds to the ratio $\mathrm{BC} / \mathrm{AC}=28 \%$.

Figure 3(b) gives the evolution of the observed long term leakage rate as a function of $\theta$. For completeness the long term leakage rate (defined by 5 ) is also depicted.

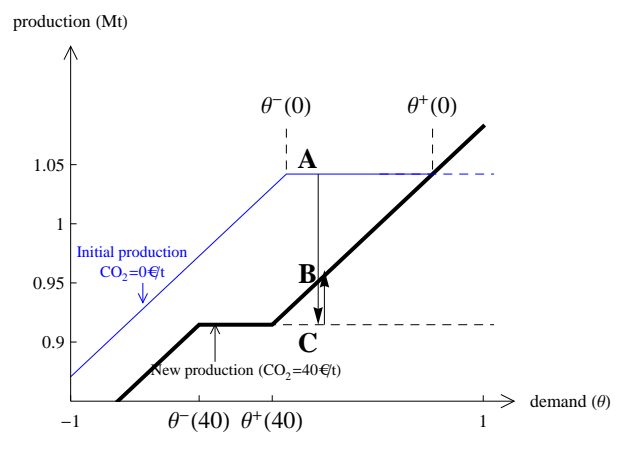

(a) Production

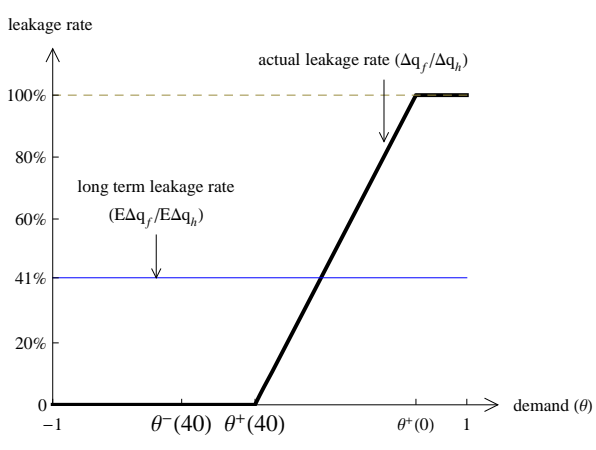

(b) Leakage rate

Figure 3: Production and the observed long term leakage rates for each $\theta$.

A sensitivity analysis of the long term leakage rate with respect to the $\mathrm{CO}_{2}$ price and the demand variability is made. The results are given in Table 2. It is increasing in both dimensions. Recall that the short term leakage rate is zero. Recall also that, without demand uncertainty, by construction there would not be any leakage in our model. 


\begin{tabular}{|c|c|c|c|c|c|}
\hline & \multicolumn{4}{|c|}{$\mathrm{CO}_{2}$ price } \\
\hline & & 20 & 30 & 40 & 50 \\
\hline \multirow{6}{*}{$\begin{array}{c}\text { Demand } \\
\text { Variability } \\
\quad \lambda / a\end{array}$} & $0 \%$ & $0 \%$ & $0 \%$ & $0 \%$ & $0 \%$ \\
\hline & $10 \%$ & $13 \%$ & $20 \%$ & $29 \%$ & $42 \%$ \\
\hline & $15 \%$ & $24 \%$ & $31 \%$ & $41 \%$ & $54 \%$ \\
\hline & $20 \%$ & $32 \%$ & $39 \%$ & $49 \%$ & $62 \%$ \\
\hline & $25 \%$ & $38 \%$ & $46 \%$ & $55 \%$ & $67 \%$ \\
\hline & $30 \%$ & $43 \%$ & $51 \%$ & $60 \%$ & $71 \%$ \\
\hline
\end{tabular}

Table 1: long term leakage rate (5)-the short term one is null.

\subsection{Pass-through}

The impact of the carbon price on the output price is measured by the pass through rate. This is the ratio between the output price change and the cost change. We follow the same methodology as for the leakage rate. The short term pass through rate is:

$$
P T_{S T}=\frac{\mathbb{E}\left[p\left(q\left(k_{n}^{*}\left(c_{h}\right), c_{h}+\Delta c_{h}, n, \theta\right), \theta\right)-p\left(q\left(k_{n}^{*}\left(c_{h}\right), c_{h}, n, \theta\right), \theta\right)\right]}{\Delta c_{h}}
$$

and the long term one:

$$
P T_{L T}=\frac{\mathbb{E}\left[p\left(q\left(k_{n}^{*}\left(c_{h}+\Delta c_{h}\right), c_{h}+\Delta c_{h}, n, \theta\right), \theta\right)-p\left(q\left(k_{n}^{*}\left(c_{h}\right), c_{h}, n, \theta\right), \theta\right)\right]}{\Delta c_{h}} .
$$

Without uncertainty, the model corresponds to a standard Cournot oligopoly with linear demand and constant marginal cost, there is no imports and production equals capacity. In this case - to be referred as the standard Cournot model - the short term pass through rate is null and the long term one is $n /(n+1)$.

\section{Proposition 3}

- The short term pass through rate is increasing with respect to demand variability and smaller than the long-term pass-through rate. 
- The long term pass through rate is equal to the one obtained in the standard Cournot model (it is $n /(n+1)$.)

The proof is in C.3.

We also define the observed pass through rate for each value of $\theta$. They are computed in the short term (with unchanged capacity) and in the long term (with adjusted capacity). The expressions of these rates are similar to (6) and (7) without the expectation operator. ${ }^{4}$ All these indicators are discussed in the numerical illustration below.

\section{Numerical Illustration}

The output price and the observed pass through rates, both short term and long term, are depicted in Figure 4. Three zones emerge depending on the value of $\theta$. We denote by $\theta^{+}(40), \theta^{-}(40), \theta^{+}(0)$ and $\theta^{-}(0)$ the values of the thresholds states of Lemma 1 for a $\mathrm{CO}_{2}$ price of $40 € / \mathrm{tCO}_{2}$ and $0 € / \mathrm{tCO}_{2}$ respectively; $\theta_{h}$ is the demand state in which the capacity constraint start being binding for a price of $40 € / \mathrm{tCO}_{2}$ and a capacity not adapted.

Firstly, for $\theta<\theta^{-}(40)$, capacity is not a constraint. The effect of the $\mathrm{CO}_{2}$ price on the short and long term rates is similar, the pass through in these states is $n /(n+1)$ as in a standard Cournot model. Secondly, for $1 \geq \theta>\theta^{+}(0)$, the price is set by the import cost and the pass through is null. In both cases there is no difference between short term and long term.

What happens in the median zone can be inferred from the graphs in Figure 4. The prices depicted in Figure 4a correspond to

- abcd for $\mathrm{CO}_{2}=0 € / t$,

- ehcd $\left(\mathrm{CO}_{2}=40 € / t\right)$ in the short term,

- efgcd $\left(\mathrm{CO}_{2}=40 € / t\right)$ in the long term.

The pass through rates are depicted in Figure $4(\mathrm{~b})$. The short term pass through rate is $52 \%$ and the long term one is $86 \%=n /(n+1)=6 / 7$. The observed pass through rates in each demand state are also depicted. The observed short term pass through rate remains at $6 / 7$ until $\theta^{-}(0)$ and then

\footnotetext{
${ }^{4}$ Contrary to the leakage rate the short term (resp. long term) pass through rate is the expectation of the observed short term (resp. long term) pass through rate because the denominator (the change of the $\mathrm{CO}_{2}$ price) is constant across demand states.
} 
progressively decreases to zero at $\theta_{h}\left(\theta_{h}=0.4\right.$ in the numerical illustration) and then remains at zero.

The observed long term pass through rate increases from $6 / 7$ for $\theta^{-}(40)<$ $\theta<\theta^{+}(40)$. It remains constant for $\theta^{+}(40)<\theta<\theta^{-}(0)$. It decreases to zero for $\theta^{-}(0)<\theta<\theta^{+}(0)$. The peak can be computed to be at $171 \%$, which is well above $100 \%$ ! It occurs because the adapted capacity creates a constraint while there was none without the $\mathrm{CO}_{2}$ price increase.

The introduction of demand variations has a major impact on the pass through rates. The observed pass through rates, both the short term and the long term rates, depart from the one in a standard Cournot model. In particular they will be lower in high demand states such as the period corresponding to the first EU-ETS (2005-2008). The average short term pass through rate is $52 \%$ which is much lower than in a standard Cournot model i.e. $6 / 7=86 \%$.

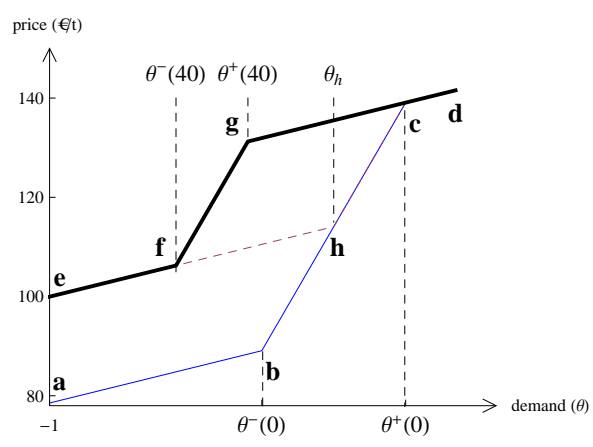

(a) Price

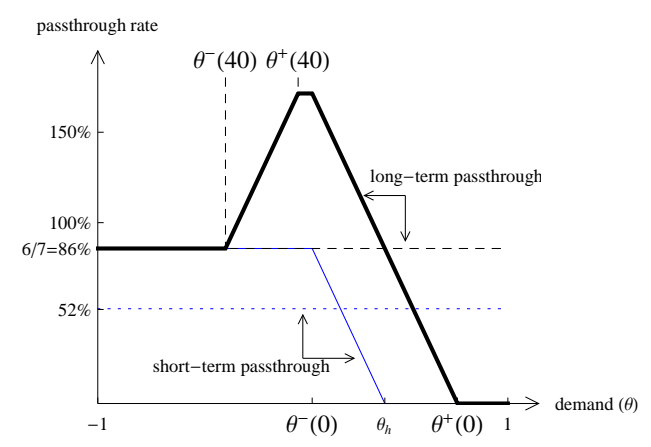

(b) Passthrough rate

Figure 4: Changes in output prices and the passthrough rates in each demand state $(\theta)$.

A sensitivity analysis of the short term pass through rate with respect to the $\mathrm{CO}_{2}$ price and demand variability is made. The results are given in Table 3. It is slightly increasing in both dimensions, from $49 \%$ to $57 \%$. Recall that the standard Cournot rate is $6 / 7=86 \%$, which is much higher. 


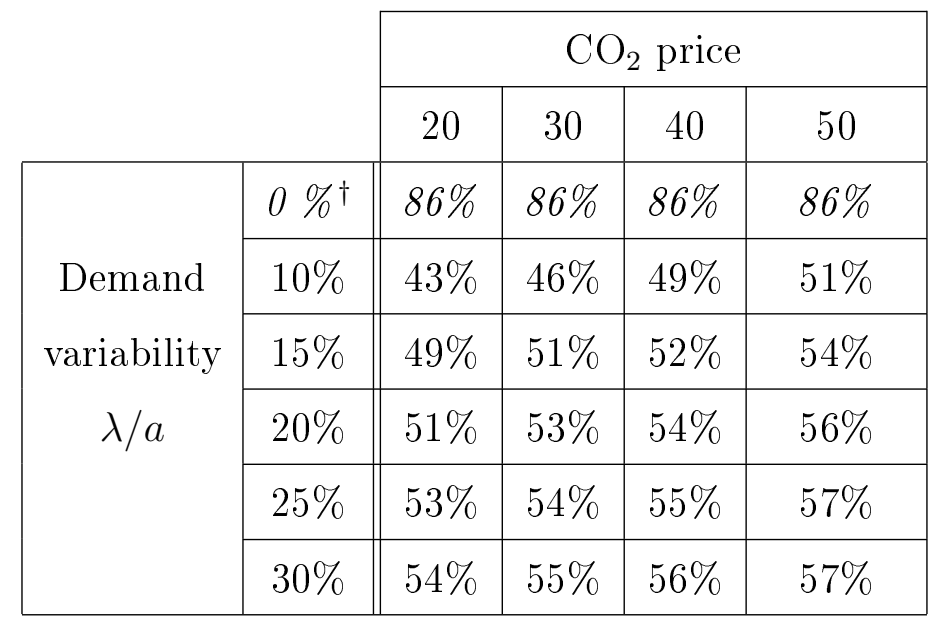

$\dagger$ This row corresponds to the "standard Cournot model"

Table 2: Short term pass through rate $(6)$.

\section{Conclusion}

In some energy intensive industries it has been empirically observed that competition is dominated by multinationals which optimize their current production through their international network of plants. To meet the regional demand at home, home plants are used in priority to imports, unless the capacity of these plants is saturated. As a consequence imports only occur in high demand states at home. We formalize such a context and show how in the long term capacities are adjusted to a unilateral change in the $\mathrm{CO}_{2}$ price at home. The induced leakage and pass through rates are derived both in the short term (without capacity adjustments) and in the long term (with capacities adjustments). We show that the leakage rates and the pass through rates are higher in the long term than in the short term.

The channel of carbon leakage explored in this paper had not been formally identified so far. While our results are purely conceptual we think they may be relevant in a number of empirical situations.

Our qualitative results on short term and long term effects seem to be in line with the comments reported in Ellerman et al. (2010) regarding the first phases of the EU-ETS. The authors emphasize the lack of short term effects and the potential long term ones. Our results may also be relevant for 
the evaluation of the free allocation mechanism introduced in the EU-ETS post 2013 for sensitive sectors. This mechanism is based on past production and new capacities, and not on updated production (European Commission, 2011). In Meunier et al. (2012) we build on our model to explore the economic properties of such mechanisms to mitigate leakage in the cement sector, a sector in which the channel of leakage identified in the present paper is relevant.

Another context for application could concern the electricity sector, a sector with strong capacity constraint and large demand variability. Though international trade is low, regional trade is not. The development if unilateral regional trading scheme in California did put the leakage issue for electricity on the policy agenda (Hood, 2010). Bushnell and Chen (2012) do introduce capacity constraints in their analysis of leakage but do not consider the long term effect of the scheme on capacity choices.

To better cope with more empirical situations several extensions of our model would be helpful. It would be interesting to relax some of our assumptions, such as the introduction of foreign firms with no plants at home, and explicitly introduce assumptions about the rest of the world (correlation in regional business cycles and capacity decisions). One should also allow for more general demand and cost functions, and possibly dynamics based on a Markov framework allowing for endogenous market structures, along the line introduced in Ryan (2012).

\section{Acknowledgements}

Financial support is gratefully acknowledged from the Ecole Polytechnique chair EDF-Sustainable Development, and the Business Sustainability Initiative at Europlace Institute of Finance.

\section{References}

Babiker, M. H., 2005, Climate change policy, market structure, and carbon leakage. Journal of international Economics, 65(2), 421-445.

Balistreri, E. J., and Rutherford, T. F., 2012, Subglobal carbon policy and the competitive selection of heterogeneous firms. Energy Economics 34(S2), S190-S197 
Brander, J. A., 1981, Intra-industry trade in identical commodities. Journal of International Economies 11(1), 1-14.

Böhringer, C., Balistreri, E.J. and Rutherford, T.F., 2012. The Role of Border Carbon Adjustment in Unilateral Climate Policy: Results from EMF 29. Christoph Böhringer, Edward J. Balistreri and Thomas F. Rutherford, eds, Energy Economics, 34(S2), S95-S250.

Barrett, S., 1994, Self-Enforcing International Environmental Agreements, Oxford Economic Papers, 46, pp. 878-894.

Bushnell, J. and Chen, Y., 2012, Allocation and leakage in a regional capand-trade markets for $\mathrm{CO}_{2}$, Resource and Energy Economics, 34(4), pp. 647-668.

Carraro, C. and Siniscalco, D., 1993, Strategies for the international protection of the environment, Journal of Public Economics 52(3), pp 309-328.

Demailly, D. and Quirion, P., 2008. Leakage from climate policies and border tax adjustment: lessons from a geographic model of the cement industry, in: R. Guesnerie, H. Tulkens (Eds), The Design of Climate Policy, The MIT Press, Boston, MA, 333-358.

Droege, S. and Cooper, S., 2009. Tackling leakage in a world of unequal carbon prices, a study of the Greens/EFA Group, Climate strategies, May.

European Commission, 2011. Determining Transitional Union-wide Rules for Harmonised free Allocation Pursuant to Article 10a of Directive 2003/87/EC, Commission Decision, 24.4.2011.

Ellerman, A., Convery, F., De Perthuis, C. and Alberola, E., 2010. Pricing carbon: the European Union emissions trading scheme, Cambridge Univ Pr.

Elliott, J. and Fullerton, D., 2013. Can a Unilateral Carbon Tax Reduce Emissions Elsewhere? CESifo Working Paper Series from CESifo Group Munich No 4113.

Felder, S., Rutherford , T., 1993. Unilateral $\mathrm{CO}_{2}$ reductions and carbon leakage: the consequences of international trade in oil and basic materials. Journal of Environmental Economics and Management 25(2): 162-176. 
Fischer, C. and Fox, A. K., 2012, Comparing policies to combat emissions leakage: Border carbon adjustments versus rebates, Journal of Environmental Economics and Management 64(2): 199-216.

Gerlagh, R. and Kuik, O., 2007. Carbon Leakage With International Technology Spillovers. FEEM Working Paper No. 33.2007

Golombek, R. and Hoel, M., 2004. Unilateral Emissions Reductions and Cross-Country Technology Spillovers, Advances in Economic Analysis \& Policy 3(2).

Grubb, M. and Neuhoff, K. ,2006. Allocation and competitiveness in the EU emissions trading scheme: policy overview, Climate Policy 6: 7-30.

Hood, C., 2010, Reviewing existing and proposed emissions trading systems. IEA http://www.iea.org/papers/2010/ets\_paper2010.pdf .

Hourcade, J.-C., Demailly, D., Neuhoff, K. and Sato, M., 2008. Differentiation and dynamics of EU ETS competitiveness impacts: final report, Report, Climate Strategies, Cambridge, section 3: 60-93.

Krugman P., 1979, Increasing Retrns, Monopolistic competition, and International Trade. Journal of International Economics 9: 469-479.

Krugman, P., 1980, Scale Economies, Product Differentiation, and the Pattern of Trade. The American Economic Review, 70(5): 950-959.

Meunier, G. and Ponssard, J.-P., 2012. A Sectoral Approach Balancing Global Efficiency and Equity. Environmental and Resource Economics 53(4): 533-552

Meunier, G., Ponssard, J.-P., and Quirion, P., 2012. Carbon Leakage and Capacity-Based Allocations. Is the EU right? Ecole Polytechnique, Cahier $n^{\circ}$ 2012-36. http: //hal .archives-ouvertes.fr/docs/00/ 76/00/61/PDF/2012-36.pdf

Oliveira Martins, J., 1995. Unilateral emission control, energy-intensive industries and carbon leakage. In Global Warming: Economic Dimensions and Policy Responses. OECD, Paris (1995).

Ponssard, J. and Walker, N. 2008. Eu emissions trading and the cement sector: a spatial competition analysis, Climate Policy 8: 467-493. 
Reinaud, J. 2005. Industrial competitiveness under the European Union emissions trading scheme, International Energy Agency.

Rutherford, T., 1992. The welfare effects of fossil fuel carbon restrictions: results from a recursively dynamic trade model. OECD Economics Department Working Paper, no. 112.

Ryan, S.P., 2012, The costs of environmental regulation in a concentrated industry, Econometrica 80(3): 1019-1061

WBCSD, 2009 . A sectoral approach. cement sustainability initiative., Cement Sustainability Initiative, World Business Council for Sustainable Development, Geneva.Geneva.

\section{Appendix}

\section{A The numerical illustration}

The data corresponding to the numerical illustration is given in Table 1 . This data is illustrative of the EU cement industry and originates from Ponssard and Walker (2008). The demand function is calibrated such that at the Cournot equilibrium with 6 firms without uncertainty, each firm produces 1 $\mathrm{Mt}$, the market price is $100 € / \mathrm{t}$ and the price elasticity at the equilibrium is -0.27 .

The demand fluctuations captured through the parameter $\lambda / a$ corresponds to the average demand fluctuations of a European country over the last 20 years. The variable costs in $€$ per ton of cement are: for investment $c_{k}=15$ (annualized over a 40 years life duration for a plant), for home production $c_{h}=25$, for import $c_{f}=75$ (involving sea transport, terminal cost and further inland transportation by road; it is suggestive of an inland region). We consider the implementation of a $\mathrm{CO}_{2}$ price of $40 € / \mathrm{tCO}_{2}$ and an emission rate of $.65 \mathrm{tCO}_{2}$ per ton of cement, so $\Delta c_{h}=25$. 


\begin{tabular}{|c|c|}
\hline \multicolumn{2}{|c|}{$\begin{array}{c}\text { Cost parameters } \\
(€ / \mathrm{t})\end{array}$} \\
\hline$c_{k}$ & 15 \\
$c_{h}$ & 25 \\
$c_{f}$ & 75 \\
$\Delta c_{h}$ & $40 € / \mathrm{tCO}_{2} \times 0.65=25$ \\
\hline
\end{tabular}

\begin{tabular}{|c|c|}
\hline \multicolumn{2}{|c|}{ Demand Parameters } \\
\hline $\mathrm{a}(€ / \mathrm{t})$ & 470 \\
$\mathrm{~b}\left(€ / \mathrm{t}^{2}\right)$ & 61.7 \\
$\lambda / a$ & $15 \%$ \\
\hline
\end{tabular}

Table 3: Parameters for the illustration

\section{B Proof of Lemma 1}

\section{Expression of the thresholds}

We first express the thresholds $\theta^{-}$and $\theta^{+}$in the short-term, with a fixed capacity $k$.

If demand varies sufficiently (large $\lambda$ ) at the low (resp. high) threshold state $\theta^{-}$(resp. $\left.\theta^{+}\right)$the unconstrained monopoly production with marginal $\operatorname{cost} c_{h}$ (resp. $c_{f}$ ) is precisely equal to the capacity. For small $\lambda$ the thresholds are -1 or 1 respectively. This gives:

$$
\begin{aligned}
& \theta^{-}=\max \left\{\left(2 b k-a+c_{h}\right) / \lambda,-1\right\} \\
& \theta^{+}=\min \left\{\left(2 b k-a+c_{f}\right) / \lambda, 1\right\}
\end{aligned}
$$

\section{The monopoly capacity}

The monopoly long term profit is a strictly concave function of $k \in[0,(a+$ $\left.\lambda-c_{h}\right) / 2 b$. There is a unique profit maximizing capacity $k^{*}$ that solves the first order condition:

$$
\frac{1}{2} \int_{\theta^{-}}^{\theta^{+}}\left(p+p^{\prime} k\right)-c_{h} d \theta+\frac{1}{2} \int_{\theta^{+}}^{1}\left(c_{f}-c_{h}\right) d \theta=c_{k}
$$

Four situations can arise whether at $k^{*}: \theta^{-}=-1$ or not and $\theta^{+}=1$ or not. The level of demand variability and the cost parameters determine in which situation we are. We limit ourselves to the case in which the demand 
variability is sufficiently large so that $\theta^{-}>-1$ and $\theta^{+}<1$ (the expressions in the other situations could be obtained by request to the authors).

In that case, $a+\lambda \theta^{-}-2 b k=c_{h}$, and $a+\lambda \theta^{+}=c_{f}$. Equation (10) is:

$$
\begin{aligned}
2 c_{k} & =\int_{\theta^{-}}^{\theta^{+}}\left[(a-2 b k)+\lambda \theta-c_{h}\right] d \theta+\left(1-\theta^{+}\right)\left(c_{f}-c_{h}\right) \\
& =\int_{\theta^{-}}^{\theta^{+}} \lambda\left(\theta-\theta^{-}\right) d \theta+\left(1-\theta^{+}\right)\left(c_{f}-c_{h}\right) \\
& =\lambda\left(\theta^{+}-\theta^{-}\right)^{2} / 2+\left(1-\theta^{+}\right)\left(c_{f}-c_{h}\right) .
\end{aligned}
$$

Therefore, the two thresholds satisfy the equations:

$$
\theta^{+}-\theta^{-}=\frac{c_{f}-c_{h}}{\lambda} \text { and } \theta^{+}=1+\frac{c_{f}-c_{h}}{2 \lambda}-\frac{c_{k}}{c_{f}-c_{h}}
$$

Replacing $\theta^{+}$in (14) by its expression (9) gives:

$$
k_{1}^{*}=\left[a-\left(c_{f}+c_{h}\right) / 2+\lambda\left(1-2 c_{k} /\left(c_{f}-c_{h}\right)\right)\right] / 2 b .
$$

The thresholds are indeed respectively higher than -1 and lower than 1 if and only if $\lambda$ is sufficiently large:

$$
\begin{aligned}
\left(2 b k^{*}-a+c_{h}\right) / \lambda>-1 & \Leftrightarrow \lambda>\left(c_{f}-c_{h}\right)^{2} / 4\left(c_{f}-c_{h}-c_{k}\right), \\
\left(2 b k^{*}-a+c_{f}\right) / \lambda<1 & \Leftrightarrow \lambda>\left(c_{f}-c_{h}\right)^{2} / 4 c_{k} .
\end{aligned}
$$

\section{The oligopoly capacity}

A sketch of the proof is provided, a more detailed one can be obtained by request to the authors.

Assume that there are $n$ firms. Each firm simultaneously chooses its capacity and a production plan. At an equilibrium: on the short term, in each demand state firms play a constrained Cournot game with two technologies available, and, in the long term, each firm capacity is a solution of a first order equation that equalizes the capacity $\operatorname{cost} c_{k}$ with expected short term marginal profit. Any equilibrium is symmetric because the expected marginal short term profit of two firms is equal if and only if their capacities are equal. Then the only possible equilibrium is symmetric and the aggregate equilibrium capacity $k_{n}^{*}$ is the unique solution of equation:

$$
\int_{\theta^{-}(n, k)}^{\theta^{+}(n, k)}\left(a-c_{h}+\lambda \theta-\frac{n+1}{n} b k\right) d \theta+\int_{\theta^{+}(n, k)}^{1}\left(c_{f}-c_{h}\right) d \theta-2 c_{k}=0
$$


where $\theta^{-}(n, k)$ and $\theta^{+}(n, k)$ are :

$$
\begin{aligned}
& \theta^{-}=\max \left\{\left((n+1) b k / n-a+c_{h}\right) / \lambda,-1\right\}, \\
& \theta^{+}=\min \left\{\left((n+1) b k / n-a+c_{f}\right) / \lambda,+1\right\},
\end{aligned}
$$

and aggregate equilibrium productions $q_{h}\left(k, c_{h}, n, \theta\right)$ and $q_{f}\left(k, c_{h}, n, \theta\right)$ are the constrained Cournot one:

$$
\left.\begin{array}{cl}
0 \leq \theta \leq \theta^{-} \quad: \quad q_{h}=n\left(a+\lambda \theta-c_{h}\right) /(n+1) \text { and } q_{f}=0 \\
\theta^{-} \leq \theta \leq \theta^{+} \quad: \quad q_{h}=k \text { and } q_{f}=0 \\
\theta^{+} \leq \theta \leq 1 \quad: \quad q_{h}=k \text { and } q_{f}=n\left(a+\lambda \theta-c_{f}\right) /(n+1)-k
\end{array}\right\}
$$

By injecting expressions (17) and (18) of $\theta^{-}$and $\theta^{+}$into the first order condition (16) it appears that the thresholds are solution of an equation independent of $n$. Hence, equilibrium values of threshold states are independent of $n$ and given by (14), and the oligopoly capacity is

$$
k_{n}^{*}=\frac{n}{n+1} \frac{1}{b}\left[a-\frac{c_{h}+c_{f}}{2}+\lambda\left(1-2 \frac{c_{k}}{c_{f}-c_{h}}\right)\right] .
$$

And finally, the solution of equation (16) and the corresponding productions (19) are equilibrium strategies because individual profit of each firm is concave and first order conditions are satisfied.

\section{Results}

\section{C.1 Proof of Proposition 1}

We use the expression established in Lemma 1 . The derivatives of $k_{n}^{*}$ in equation (2) are

$$
\frac{\partial k_{n}^{*}}{\partial c_{h}}=\frac{-1}{b} \frac{n}{n+1}\left[\frac{1}{2}+\frac{2 \lambda c_{k}}{\left(c_{f}-c_{h}\right)^{2}}\right]<0 ; \frac{\partial k_{n}^{*}}{\partial \lambda \partial c_{h}}=\frac{n}{n+1} \frac{-2 c_{k}}{b\left(c_{f}-c_{h}\right)^{2}}<0 .
$$

\section{C.2 Proof of Proposition 2}

With the first-order condition (16), the derivative of $k_{n}^{*}$ satisfies $\left(\theta^{+}-\theta^{-}\right) b(n+$ 1) $/ n \partial k_{n}^{*} / \partial c_{h}=-\left(1-\theta^{-}\right)$so that $\partial k_{n}^{*} / \partial c_{h}$ can be rewritten as

$$
\frac{\partial k_{n}^{*}}{\partial c_{h}}=-\frac{1}{b} \frac{n}{n+1} \frac{1-\theta^{-}}{\theta^{+}-\theta^{-}}
$$


The expected quantity produced domestically is

$$
Q_{h}\left(k, c_{h}, \lambda\right) \underset{\text { def }}{=} \mathbb{E} q_{h}=0.5 \int_{-1}^{\theta^{-}} \frac{n}{n+1} \frac{1}{b}\left(a+\lambda \theta-c_{h}\right) d \theta+0.5 \int_{\theta^{-}}^{1} k d \theta
$$

and the expected quantity imported:

$$
Q_{f}\left(k, c_{h}, \lambda\right) \underset{\text { def }}{=} \mathbb{E} q_{f}=0.5 \int_{\theta^{+}}^{1}\left[\frac{n}{n+1} \frac{1}{b}\left(a+\lambda \theta-c_{f}\right)-k\right] d \theta .
$$

The short-term leakage rate is null because $Q_{f}$ does not depend on $c_{h}$, so the numerator of (4) is null.

The long term leakage is independent of $n$ because both the numerator and the denominator are proportional to $n /(n+1)$ (remember that $\theta^{-}$and $\theta^{+}$ are independent of $n$ at equilibrium and that $k_{n} *$ is proportional to $\left.n /(n+1)\right)$.

To determine the effect of $\lambda$ on the leakage rate, we write the long-term leakage rate as

$$
L_{L T}=\frac{\int_{0}^{\Delta c_{h}} \partial Q_{f} / \partial c_{h} d c_{h}}{\int_{0}^{\Delta c_{h}} \partial Q_{h} / \partial c_{h} d c_{h}} .
$$

From equations (21) and (22), the two derivatives of expected quantities are:

$$
\begin{aligned}
\frac{\partial Q_{f}}{\partial c_{h}} & =-0.5\left(1-\theta^{+}\right) \frac{\partial k_{n}^{*}}{\partial c_{h}} \\
-\frac{\partial Q_{h}}{\partial c_{h}} & =0.5\left[\frac{n}{n+1} \frac{1+\theta^{-}}{b}-\left(1-\theta^{-}\right) \frac{\partial k_{n}^{*}}{\partial c_{h}}\right]
\end{aligned}
$$

Let us prove that the former is increasing and the latter decreasing w.r.t. $\lambda$, this will prove that the long-term leakage rate is increasing with respect to $\lambda$ :

- From Proposition 1 the derivative of $k_{n}^{*}$ is decreasing w.r.t. $\lambda$, and from the equations (14) the equilibrium threshold $\theta^{+}$is decreasing so

$$
\frac{\partial^{2} Q_{f}}{\partial \lambda \partial c_{h}}>0
$$

- Next, using the expression (20)

$$
-\frac{\partial Q_{h}}{\partial c_{h}}=0.5 \frac{n}{n+1} \frac{1}{b}\left[1+\theta^{-}+\left(1-\theta^{-}\right) \frac{1-\theta^{-}}{\theta^{+}-\theta^{-}}\right]
$$


and $\theta^{-}$is increasing w.r.t. $\lambda$, the ratio $\left(1-\theta^{-}\right) /\left(\theta^{+}-\theta^{-}\right)$is larger than 1 and decreasing w.r.t. $\lambda$ (from Equation (20) and Proposition 1) so

$$
-\frac{\partial^{2} Q_{h}}{\partial \lambda \partial c_{h}}<0
$$

\section{C.3 Proof of Proposition 3}

We first proove the result relative to the long-term pass-through rate. We consider the derivative of the expected price denoted $\mathbb{E} p$ with respect to $c_{h}$. The total derivative is composed of two components a direct one and an indirect one:

$$
\frac{d \mathbb{E} p}{d c_{h}}=\frac{\partial \mathbb{E} p}{\partial c_{h}}+\frac{\partial \mathbb{E} p}{\partial k} \frac{\partial k^{*}}{\partial c_{h}}
$$

With the expression (19) for home production, the first term is $\partial \mathbb{E} p / \partial c_{h}=$ $0.5\left(\theta^{-}+1\right) n /(n+1)$. The second term is related to the change of capacity. A marginal change of capacity increases expected price of $\partial \mathbb{E} p / \partial k=$ $\left(\theta^{+}-\theta^{-}\right) b / 2$, and using $(20)$ :

$$
\frac{d \mathbb{E} p}{d c_{h}}=0.5\left[\left(\theta^{-}+1\right) \frac{n}{n+1}+\left(\theta^{+}-\theta^{-}\right) b \frac{\left(1-\theta^{-}\right)}{\left(\theta^{+}-\theta^{-}\right)} \frac{n}{b(n+1)}\right]=\frac{n}{n+1}
$$

Therefore, the long-term pass-through rate is

$$
P T_{L T}=\frac{1}{\Delta c_{h}} \int_{0}^{\Delta c_{h}} \frac{d \mathbb{E} p}{d c_{h}} d c_{h}=\frac{n}{n+1}
$$

Concerning, the short-term pass-through rate. It could be written

$$
P T_{S T}=\frac{1}{\Delta c_{h}} \int_{0}^{\Delta c_{h}} \frac{\partial \mathbb{E} p}{\partial c_{h}} d c_{h}
$$

- It is smaller than the long-term one because the second term of (??) is positive; so it is less than $n /(n+1)$;

- The derivative of the price $\partial \mathbb{E} p / \partial c_{h}$ is $0.5\left(1+\theta^{-}\right) n /(n+1)$, and $\theta^{-}$is increasing with respect to $\lambda$ (cf equation (8)) so $\partial \mathbb{E} p / \partial c_{h}$ is increasing w.r.t. $\lambda$ and so is the short-term pass-through rate. 